\title{
Extraction of Water-body Area from High-resolution Landsat Imagery
}

\author{
B. Chandrababu Naik, B. Anuradha \\ Department of Electronics and Communication, SVU College of Engineering, SV University, India
}

\begin{tabular}{l}
\hline Article Info \\
\hline Article history: \\
Received Apr 16, 2018 \\
Revised Jul 10, 2018 \\
Accepted Aug 2, 2018 \\
\hline
\end{tabular}

\section{Keyword:}

Index method

Landsat

MNDWI

NDMI

NDVI

NDWI

Surface water

\begin{abstract}
Extraction of water bodies from satellite imagery has been broadly explored in the current decade. So many techniques were involved in detecting of the surface water bodies from satellite data. To detect and extracting of surface water body changes in Nagarjuna Sagar Reservoir, Andhra Pradesh from the period 1989 to 2017, were calculated using Landsat-5 TM, and Landsat-8 OLI data. Unsupervised classification and spectral water indexing methods, including the Normalized Difference Vegetation Index (NDVI), Normalized Difference Moisture Index (NDMI), Normalized Difference Water Index (NDWI), and Modified Normalized Difference Water Index (MNDWI), were used to detect and extraction of the surface water body from satellite data. Instead of all index methods, the MNDWI was performed better results. The Reservoir water area was extracted using spectral water indexing methods (NDVI, NDWI, MNDWI, and NDMI) in 1989, 1997, 2007, and 2017. The shoreline shrunk in the twenty-eight-year duration of images. The Reservoir Nagarjuna Sagar lost nearly around one-fourth of its surface water area compared to 1989 . However, the Reservoir has a critical position in recent years due to changes in surface water and getting higher mud and sand. Maximum water surface area of the Reservoir will lose if such decreasing tendency follows continuously.
\end{abstract}

Copyright $@ 2018$ Institute of Advanced Engineering and Science. All rights reserved.

\section{Corresponding Author:}

B. Chandrababu Naik,

Department of Electronics and Communication,

SVU College of Engineering, SV University, India.

Email: babunaikb@gmail.com

\section{INTRODUCTION}

The remote sensing knowledge is mainly used in different areas, such as the lake, coastal zone management, shoreline change and erosion monitoring, forest for monitoring of changes, forest and vegetation changes [1], [2], disaster monitoring [3], [4], flood prediction and evaluation of water resources [5]. It is essential for agriculture (food crops), day to day life of humans, and ecosystems [6]. To accomplish the information about open surface water is most important in different scientific areas, those are surface water analysis, watershed analysis, dynamic changes of rivers, environment monitoring, present and future estimations of water resources, and flood mapping [7]-[10]. Remote sensing satellites are having 30m resolutions and they offer a huge amount of data, which is widely used for detecting and extraction of surface water areas and its dynamic changes in recent decades [11]-[17].

Identification of water is very significant for various precise estimations and human life. To detecting and extraction of surface water area from satellite data has been introduced at many more image processing techniques in the current decades. A single-band and multi-band methods were widely used in Landsat imagery for detecting and extraction of surface water area along with selected threshold value, either positive or negative value [9]. Compared with a single-band method, multi-band method was extensively used for enhancing the surface water bodies [9]. Four different satellite multi-band methods were used for extraction of surface water bodies, those are water indexing methods, including the NDVI, NDMI, NDWI, 
and MNDWI. Thus, these methods were introduced to an extraction of surface water bodies with specified threshold values being either less than zero (negative value) or greater than zero (positive value). The NDVI, NDMI, NDWI, and MNDWI for the detecting and extraction of surface water bodies from satellite imagery. By using change detection, water features can extract separately for the different years of satellite data.

The Nagarjuna Sagar Reservoir is located in Nalgonda district in Telangana state. In recent decades, there are tremendous changes in its capacity. Therefore, the dynamic changes of the Reservoir surface water area need to monitor continuously. In this study, the spatiotemporal changes of Reservoir Nagarjuna Sagar from 1989 to 2017 are investigated based on satellite-multiband water indexed methods, including NDVI, NDMI, NDWI, and MNDWI using Landsat-5 TM and Landsat-8 OLI images for extraction of the surface water body. Overall, the MNDWI were found superior to other indexes. These method is highly important for time-series analyses of extracting shorelines using any number of Landsat images in different time intervals, and it provides an important contrast that can be used to investigate shoreline changes.

\section{STUDY AREA AND DATA SETS}

The Nagarjuna Sagar Reservoir was built across the Krishna river, which is located in between Guntur District and Nalgonda District in Telangana and its geographical area surrounded flanked by latitude $16^{\circ} 34^{\prime} 55.60^{\prime \prime} \mathrm{N}$ to $16^{\circ} 56^{\prime} 44.95^{\prime \prime} \mathrm{N}$ and longitude $78^{\circ} 24^{\prime} 13.97^{\prime \prime} \mathrm{E}$ to $78^{\circ} 47^{\prime} 06.07^{\prime \prime} \mathrm{E}$ as shown in Figure 1. Water spread area is $285 \mathrm{~km} 2$ at Full Reservoir Level (FRL), The catchment Area is $214,185 \mathrm{~km} 2(82,697 \mathrm{sq} \mathrm{mi})$ and the gross storage capacity 405 TMC at FRL, In India, the Nagarjuna Sagar Reservoir is the second biggest water reservoir and it's also one of the most basic multi-purpose irrigation and hydro-electric projects in India.

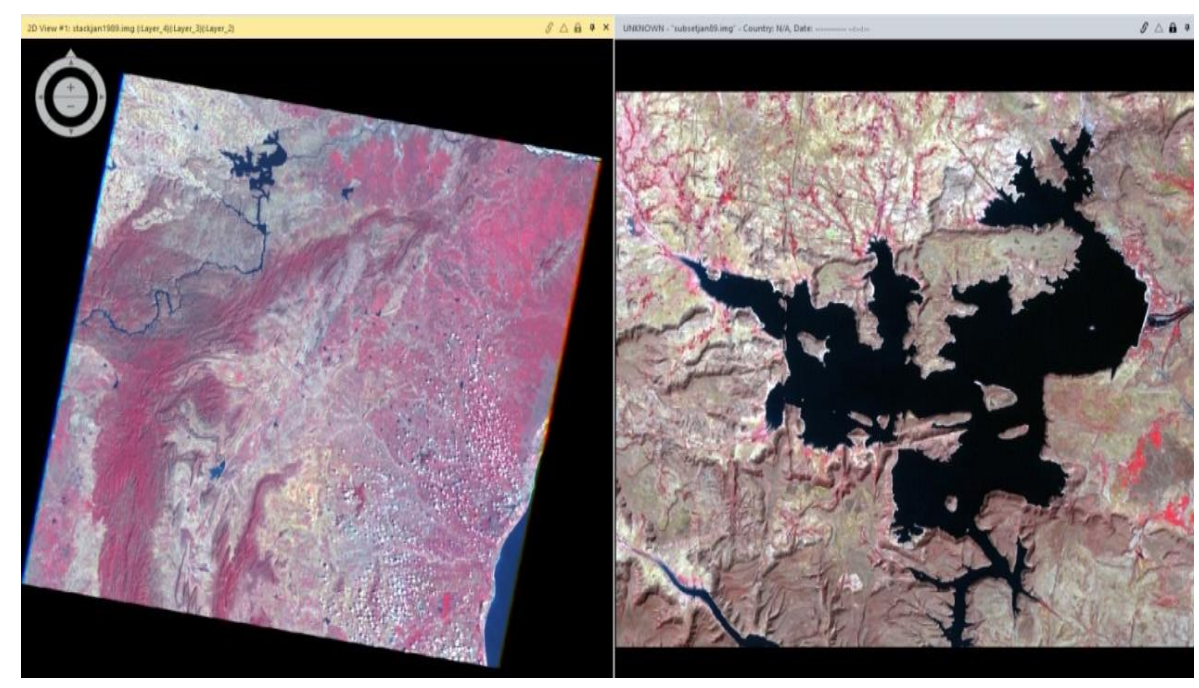

Figure 1. Location of nagarjuna sagar reservoir

The Landsat-5 TM and Landsat-8 OLI data obtained in January 1989, 1997, 2007, and 2017. These data were taken from the US Geological Survey (USGS) portal, but collected all Landsat images were cloud-free data. Table 1 represents the specification of Landsat-5 TM and Landsat-8 OLI images. The water body was extracted from satellite images with a $30 \mathrm{~m}$ spatial resolution and different band with different wavelengths as shown in Table 1.

Table 1. Landsat-5 TM and Landsat-8 OLI data with its Specifications

\begin{tabular}{lcccc}
\hline \multicolumn{1}{c}{ Satellite } & Year & Path/Row & Resolution $(\mathrm{m})$ & Wavelengths $(\mu \mathrm{m})$ \\
\hline & & & & Band1:0.45-0.52 \\
Landsat-5 & 1989 & & & Band2:0.52-0.60 \\
TM & 1997 & \multirow{2}{*}{$143 / 49$} & 30 & Band3:0.63-0.69 \\
& 2007 & & & Band4:0.76-0.90 \\
& & & Band5:1.55-1.75 \\
& & & Band7:2.08-2.35 \\
& & & Band $1: 0.433-0.453$ \\
\hline
\end{tabular}

Int J Elec \& Comp Eng, Vol. 8, No. 6, December 2018 : 4111 - 4119 
Table 1. Landsat-5 TM and Landsat-8 OLI data with its Specifications

\begin{tabular}{|c|c|c|c|c|}
\hline Satellite & Year & Path/Row & Resolution (m) & Wavelengths $(\mu \mathrm{m})$ \\
\hline & & & & Band2:0.450-0.515 \\
\hline & & & & Band3:0.525-0.600 \\
\hline Landsat-8 & 2017 & $143 / 49$ & 30 & Band4:0.630-0.680 \\
\hline \multirow{4}{*}{ OLI } & & & & Band5:0.845-0.885 \\
\hline & & & & Band6:1.560-1.660 \\
\hline & & & & Band7:2.100-2.300 \\
\hline & & & & Band9:1.360-1.390 \\
\hline
\end{tabular}

\section{METHODOLOGY}

Considered the period of 1989 to 2017, that can show the changes of water area in Reservoir. Introduces the methodology and its performances of different satellite -multiband indexes, including the Normalized Difference Vegetation Index (NDVI) [18], Normalized Difference Moisture Index (NDMI) [19], Normalized Difference Water Index (NDWI) [20], and Modified Normalized Difference Water Index (MNDWI) [12], were used for detecting and extraction of surface water bodies from Landsat imagery as shown in Table 2. Thus, four different years of satellite images (Landsat-5 data from 1989, 1997, 2007 and Landsat-8 data from 2017) were performed and extraction of surface water bodies using different indexing methods (NDVI, NDMI, NDWI, and MNDWI). Table 2. Represent the Landsat-5 data, indexes used for water feature extraction (B2: band2=green, B3: band3=red, B4: band4=near infrared, B5: band5=middle infrared. Similarly, in Landsat-8 data (B3: band3=green, B4: band4=red, B5: band5=near infrared, B6: band $6=$ middle infrared).

Table 2. Satellite-multiband Indexes used for Water Feature Extraction

\begin{tabular}{|c|c|c|c|}
\hline Index & Equation & Remark & Reference \\
\hline Normalized Difference Vegetation Index & $\mathrm{NDVI}=(\mathrm{B} 4-\mathrm{B} 3) /(\mathrm{B} 4+\mathrm{B} 3)$ & Water would be a negative value & {$[28]$} \\
\hline Normalized Difference Moisture Index & $\mathrm{NDMI}=(\mathrm{B} 4-\mathrm{B} 5) /(\mathrm{B} 4+\mathrm{B} 5)$ & Water would be a positive value & [19] \\
\hline Normalized Difference Water Index & $\mathrm{NDWI}=(\mathrm{B} 2-\mathrm{B} 4) /(\mathrm{B} 2+\mathrm{B} 4)$ & Water would be a positive value & {$[20]$} \\
\hline Modified Normalized Difference Water Index & $\mathrm{MNDWI}=(\mathrm{B} 2-\mathrm{B} 5) /(\mathrm{B} 2+\mathrm{B} 5)$ & Water would be a positive value & [12] \\
\hline
\end{tabular}

The NDWI has introduced to detect and extracting the surface water bodies with a specified threshold value. The positive threshold values for water and negative threshold values for nonwater bodies [20]. The MNDWI has introduced a powerful index to detect and extracting the surface water bodies. Because band5 (middle infrared) has replaced by the band4 (near infrared). Hence band5 reflectance's more compared with band4 [12]. The MNDWI widely used for suppressing errors from vegetation, soils, and builtup areas. The threshold values of MNDWI have positives and negatives for water and nonwater bodies. The NDVI has introduced mainly used for extracting green vegetation from other wetland surface areas. Thus, NDVI also extracts the surface water much better than NDMI indexed method, and its threshold values for water would be negative values [18]. The NDMI has introduced mainly for extracting vegetation, and water liquid but it's not much more capable of extracting water bodies as compared to others index methods (NDVI, NDWI, and MNDWI). Thus, the NDMI method was not efficient for extraction of water bodies. The NDMI threshold value of water would be a positive. Based on these analyses, the MNDWI method has performed slightly better than other index methods (NDWI, NDVI, and NDMI).

The best significance of water body extraction techniques was recognized and employed to spatiotemporal changes of the Nagarjuna Sagar Reservoir in the period 1989 to 2017. To detect and extracting Reservoir surface water bodies in four different years, such as Landsat-5 $(1989,1997,2007)$ and Landsat-8 (2017) images. Out of four-year analyses of extracting Reservoir surface water area, the maximum changes occur in the period of 2007-2017. In order to get the efficiency of detection and extraction of surface water area, different accuracy analyses were performed. By using accuracy assessment analyses, calculate the parameters are overall accuracy, producer's accuracy, user's accuracy, and kappa coefficient. Those parameters were performed over the changes of water body in the period 1989 to 2017.

\section{RESULTS AND ANALYSIS}

Once the required satellite data obtained, The image processing techniques have been involved for further processing. The analyses were performed before applying water indexed methods as shown in Figure 2 (a-d). And after applying water indexed methods, obtained the results as shown in Figures 3,4,5, and Figure 6 (a-d). Different satellite-multiband water indexed methods, including NDVI, NDMI, NDWI, and 
MNDWI were used to detect and extract the surface water body from the Landsat-5 $(1989,1997,2007)$ data and Landsat-8 (2017) data.

The four spectral water indexed methods (NDVI, NDMI, NDWI, and MNDWI) are applied to the Reservoir water area to highlight the differences between water and non-water bodies as shown in Figures 3,4,5, and 6 (a-d). Out of all water indexed methods, the MNDWI has the better method for separating water bodies as compared to other indexed methods (NDVI, NDWI, and NDMI). Generally, threshold values of water areas having greater than zero values and vegetation areas having negative values. First, calculate surface water area and changed surface water area for four different years with selected Reservoir as shown in Table 4. Similarly, calculate the surface perimeter and changed surface perimeter for four different years with same Reservoir ass hwon in Table 5.

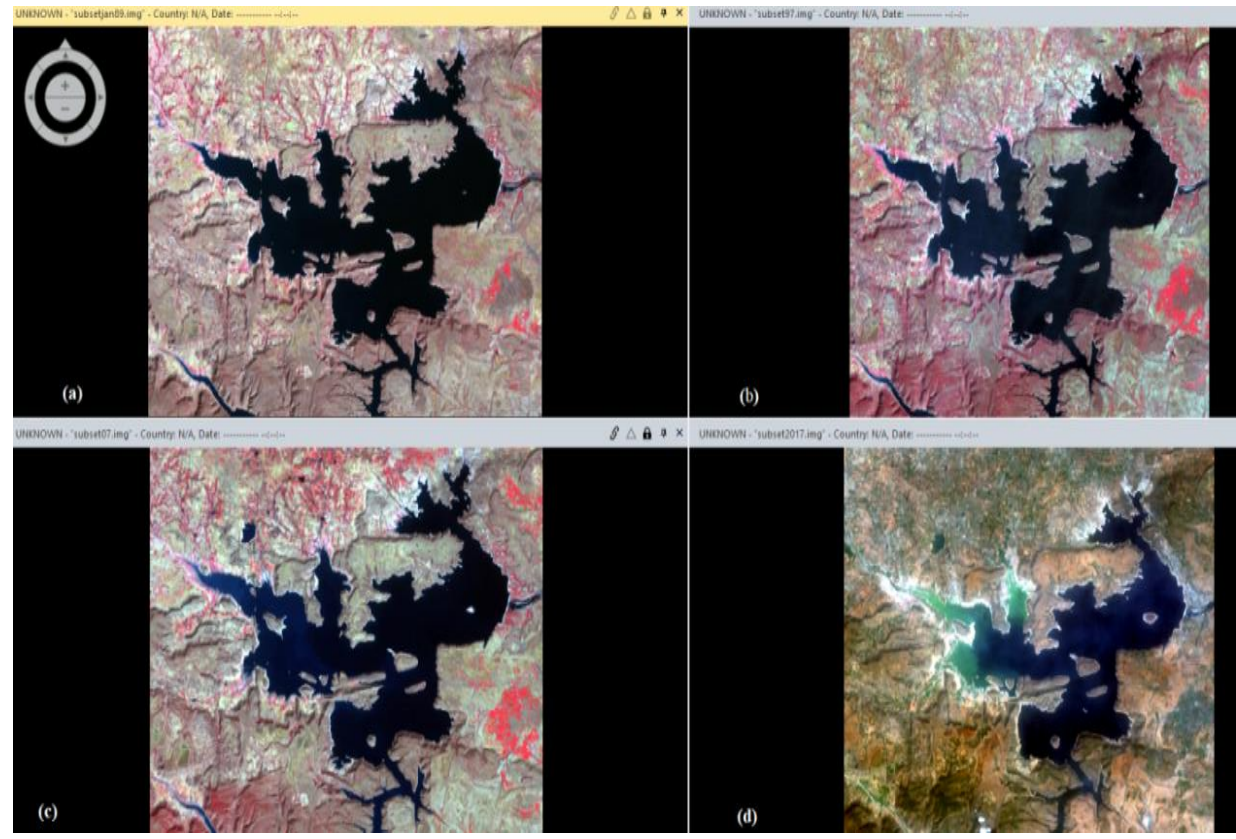

Figure 2. Landsat-5 TM image from 1989 (a); Landsat-5 TM image from 1997 (b); Landsat-5 TM image from 2007 (c); Landsat-8 OLI image from 2017 (d)

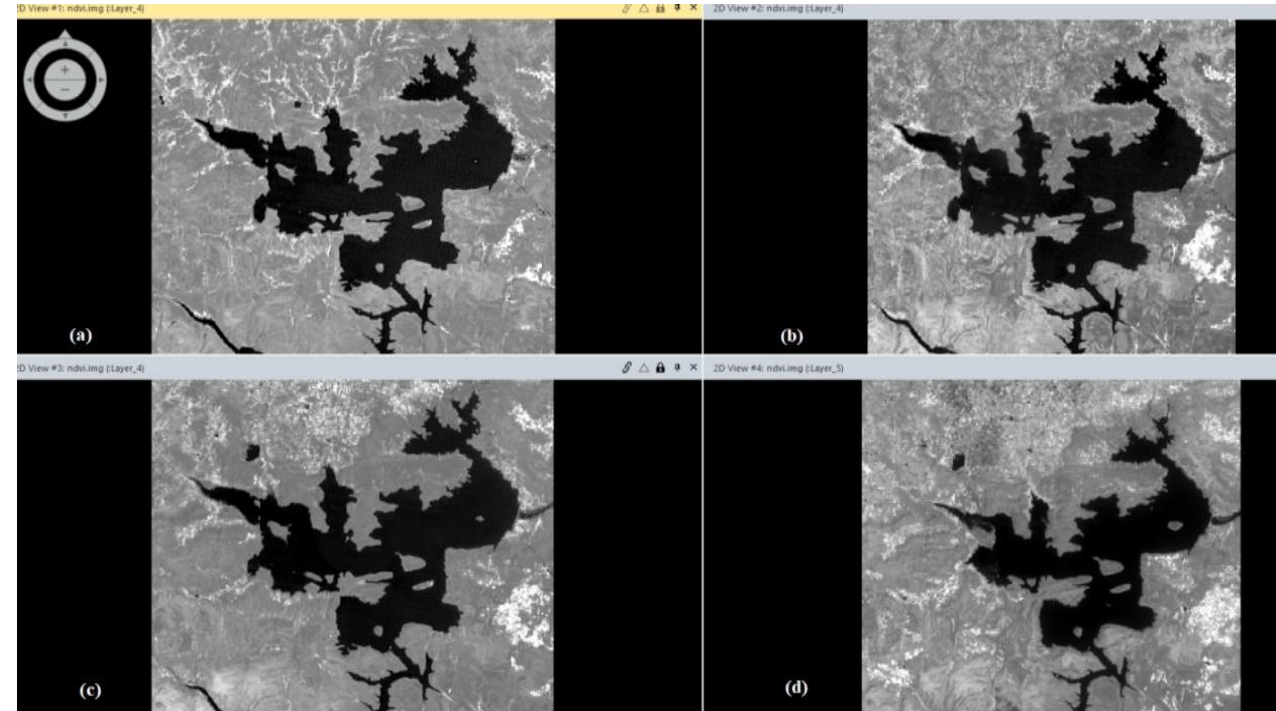

Figure 3. NDVI-based extracts water body from the Landsat-5 TM image 1989,1997, and 2007 (a-c); Landsat-8 OLI image 2017 (d) 

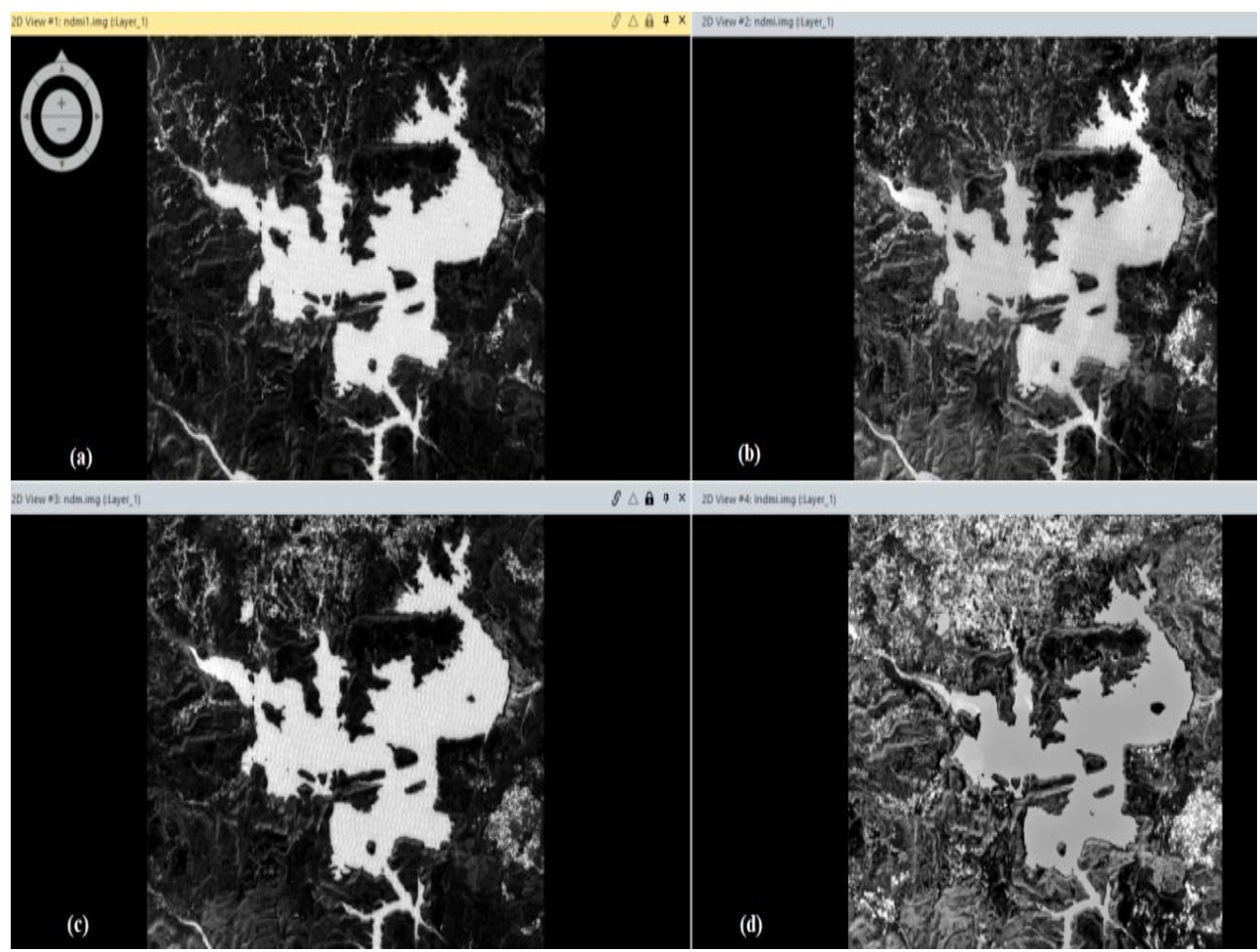

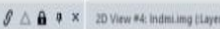

Figure 4. NDMI-based extracts water body from the Landsat-5 TM image 1989,1997, and 2007 (a-c); Landsat-8 OLI image 2017 (d)
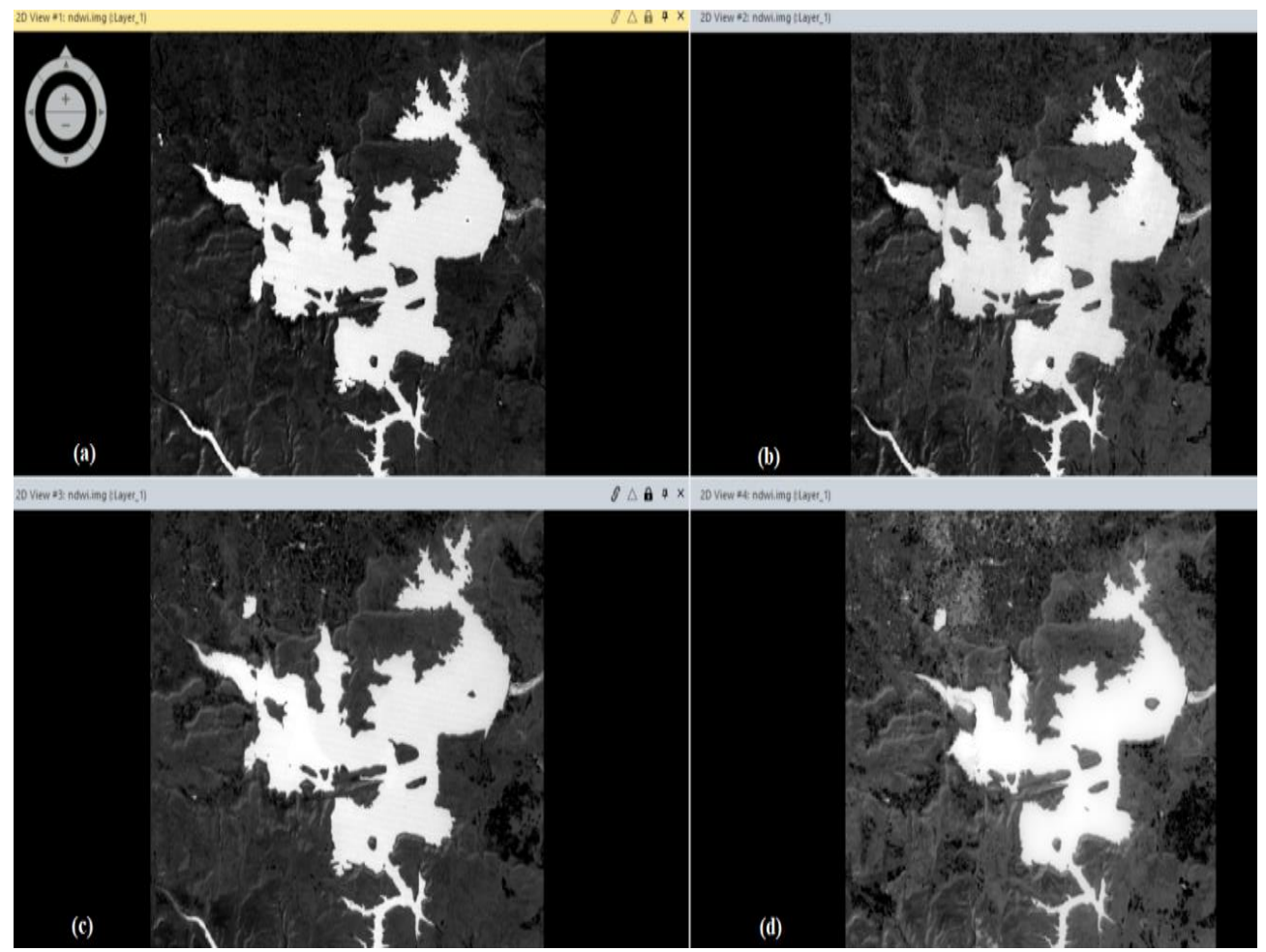

Figure 5. NDWI-based extracts water body from the Landsat-5 TM image 1989,1997, and 2007 (a-c); Landsat-8 OLI image 2017 (d) 

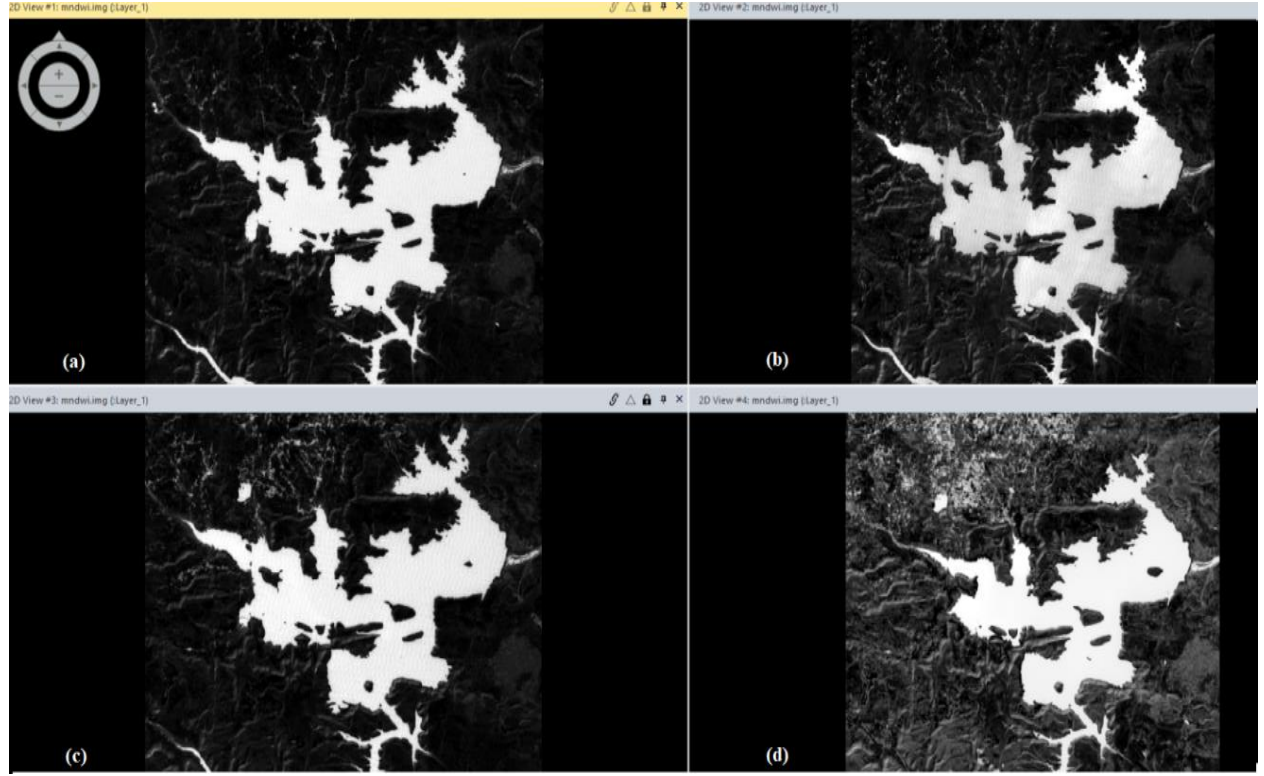

Figure 6. MNDWI-based extracts water body from the Landsat-5 TM image 1989,1997, and 2007 (a-c); Landsat-8 OLI image 2017 (d)

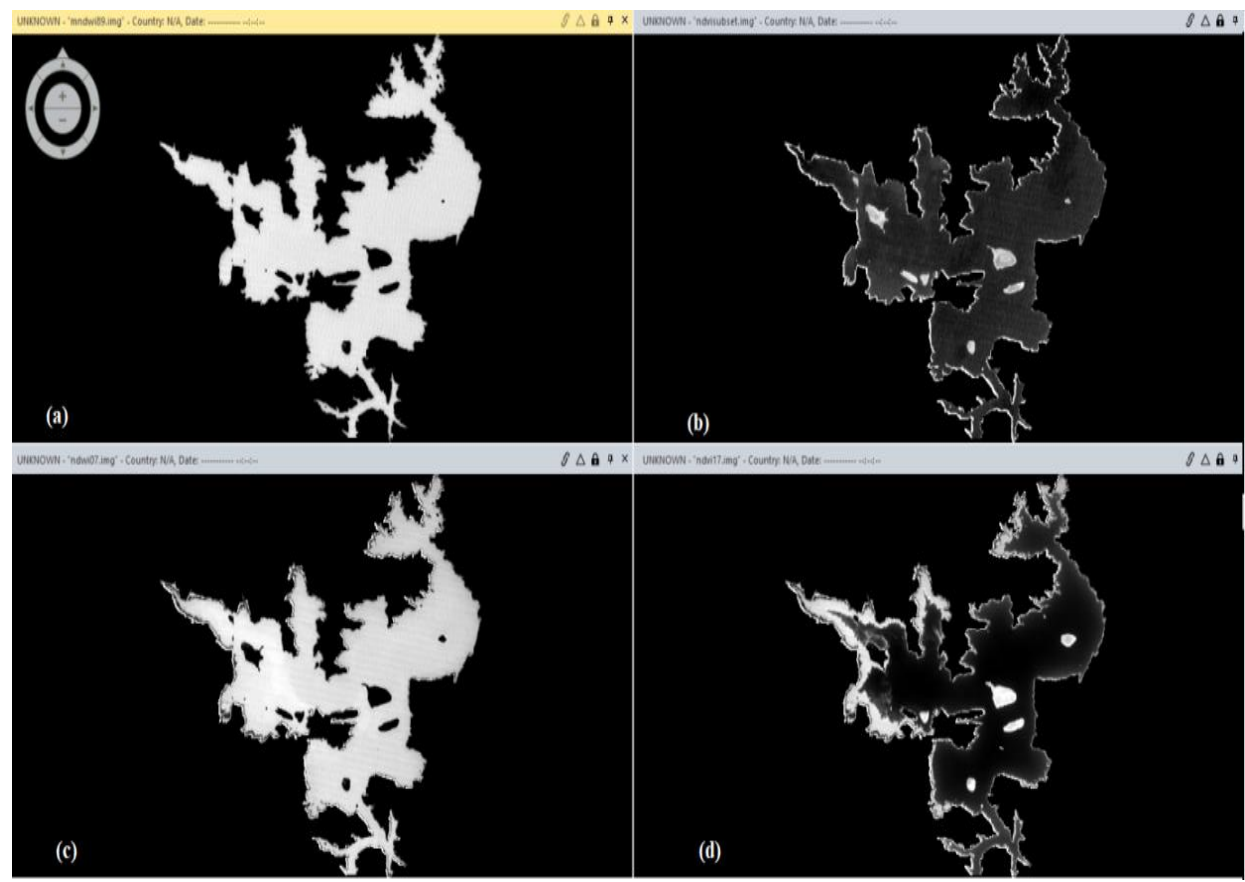

Figure 7. Changes in the area of Reservoir Nagarjuna Sagar generated using (a) MNDWI 1989; (b) MNDWI and NDVI 1989 and 1997; (c) MNDWI, NDVI and NDWI 1989, 1997, and 2007; (d) MNDWI, NDWI and NDVI 1989, 1997, 2007 and 2017.

\subsection{Evaluation of the changes}

The Reservoir water area was extracted using Unsupervised classification and spectral water indexing methods in 1989, 1997, 2007, and 2017. The shoreline shrunk in the twenty-eight-year duration of images. However, the Reservoir has been in a critical situation in recent years due to changes in surface water and getting higher mud and sand. According to the NDVI, NDMI, NDWI, and MNDWI, between 1989 and 2007 there were little bit changes in Reservoir water area, and the changes between 2007 and 2017 there was maximum changes in Reservoir water area as shown in Figure 7. The NDVI, NDMI, NDWI, and MNDWI 
results expose that the surface area of Reservoir Nagarjuna Sagar in January 1989, 1997, 2007, and 2017 was approximately $205 \mathrm{~km}^{2}, 203 \mathrm{~km}^{2}, 196 \mathrm{~km}^{2}$, and $160 \mathrm{~km}^{2}$ as shown in Table 3 . The result show that the Reservoir surface water body changes around $2.131 \mathrm{~km}^{2}$ between 1989 to $1997,6.494 \mathrm{~km}^{2}$ between 1997 to 2007, $36.016 \mathrm{~km}^{2}$ between 2007 to 2017 . The overall changes in surface water around $44.641 \mathrm{~km}^{2}$ between 1989 to 2017 as shown in Table 4.

Table 3. Performance Evaluation of The Satellite-multiband Indexes used for Surface Water Extraction

\begin{tabular}{cccccccc}
\hline \multirow{2}{*}{ Indexes } & Year & $\begin{array}{c}\text { Min } \\
\text { Threshold }\end{array}$ & $\begin{array}{c}\text { Max } \\
\text { Threshold }\end{array}$ & Mean & $\begin{array}{c}\text { Standard } \\
\text { Deviation }\end{array}$ & Perimeter $(\mathrm{km})$ & Area $\left(\mathrm{km}^{2}\right)$ \\
\hline \multirow{3}{*}{ NDVI } & 1989 & -0.555 & 0.716 & 0.034 & 0.132 & 258.095 & 205.574 \\
& 1997 & -0.290 & 0.613 & 0.068 & 0.128 & 257.113 & 203.443 \\
& 2007 & -0.375 & 0.672 & 0.040 & 0.155 & 252.296 & 196.949 \\
& 2017 & -0.582 & 0.416 & 0.119 & 0.083 & 212.021 & 161.529 \\
\multirow{5}{*}{ NDMI } & 1989 & 0.311 & 0.745 & 0.186 & 0.145 & 264.112 & 201.555 \\
& 1997 & 0.304 & 0.774 & 0.282 & 0.152 & 260.436 & 201.101 \\
& 2007 & 0.334 & 0.778 & 0.318 & 0.182 & 254.346 & 192.115 \\
& 2017 & 0.323 & 0.782 & 0.433 & 0.173 & 216.170 & 160.933 \\
NDWI & 1989 & 0.607 & 0.924 & 0.446 & 0.188 & 261.423 & 204.229 \\
& 1997 & 0.635 & 0.918 & 0.505 & 0.187 & 259.029 & 201.630 \\
& 2007 & 0.613 & 0.923 & 0.475 & 0.207 & 252.034 & 195.679 \\
MNDWI & 2017 & 0.623 & 0.987 & 0.544 & 0.198 & 211.232 & 161.411 \\
& 1989 & 0.603 & 0.936 & 0.214 & 0.256 & 263.827 & 203.784 \\
& 2007 & 0.601 & 0.950 & 0.250 & 0.236 & 258.978 & 201.879 \\
& 2017 & 0.610 & 0.948 & 0.299 & 0.269 & 252.152 & 194.783 \\
\end{tabular}

Table 4. Statistics of the Reservoir Surface Area Changes

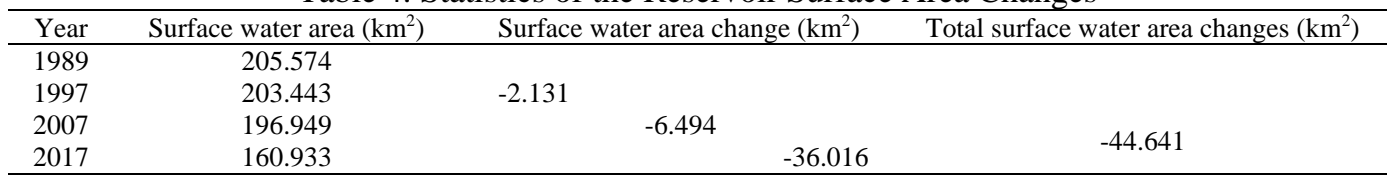

Similarly, The NDVI, NDMI, NDWI, and MNDWI results expose that the surface perimeter of Reservoir Nagarjuna Sagar in January 1989, 1997, 2007, and 2017 was approximately 264 km, 260 km, 254 $\mathrm{km}$, and $216 \mathrm{~km}$ as shown in Table 3 . The result show that the Reservoir surface perimeter changes around $3.676 \mathrm{~km}$ between 1989 to $1997,6.090 \mathrm{~km}$ between 1997 to 2007, $38.176 \mathrm{~km}$ between 2007 to 2017 . The overall changes in surface perimeter around $47.942 \mathrm{~km}$ between 1989 to 2017 as shown in Table 5 . The result show that decreasing surface water area in Reservoir from the period 1989 to 2017, and by observing the resulting analyses of maximum changes in the surface water body, as well as surface perimeter, occurred in the period 2007 to 2017. The Reservoir Nagarjuna Sagar lost nearly around one-fourth of its surface area compared to 1989. The maximum surface water area changes are observed in the western region and western - north parts of the Reservoir.

Table 5. Statistics of the Reservoir Surface Perimeter Changes

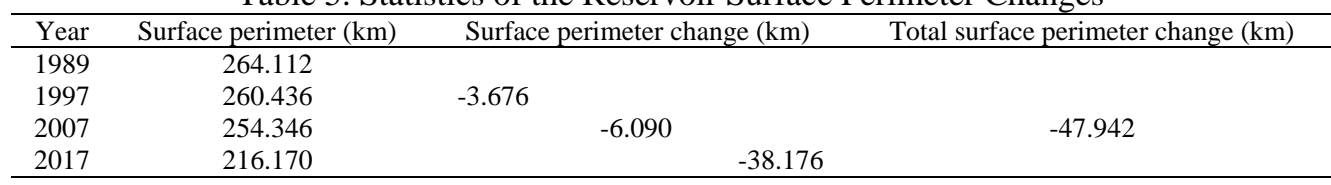

\subsection{Accuracy assessment analyses}

The probability (\%) that the classifier has labeled an image pixel into the ground truth Class. It is the probability of a reference pixel being correctly classified. Producer's accuracy: It represent pixels that belong to the truth class but fail to be classified into the proper class (omission error $=$ number of correctly classified pixels in each category per total number of classified pixels in that category (column total)), User's accuracy: Reliability, probability a pixel class on the map represents the category on the ground (commission error=number of correctly classified pixels in each category per total number of classified pixels in that category (row total)), Overall accuracy: The overall accuracy=Total number of correctly classified pixels (diagonal) per total number of reference pixels, Kappa coefficient $\left(\mathrm{K}_{\text {hat }}\right)$ : It measure of agreement between 
the classification map and the reference data. a discrete multivariate technique of use in accuracy assessment. $\mathrm{K}_{\text {hat }}>0.80$ represent strong agreement and good accuracy. $K_{\text {hat }}=0.40-0.80$ is middle, $K_{\text {hat }}<0.40$ is poor.

$$
\text { Kappa Coefficient }=\frac{(\text { TS X TCS })-\sum(\text { COL.TOTAL X ROW.TOTAL })}{\text { TS }^{2}-\sum(\text { COL.TOTAL X ROW.TOTAL })} \text { X100 }
$$

Where, TS=Total number of Samples, TCS=Total number of Correct Samples.

Statistical parameters of the accuracy assessment result show that MNDWI achieved $1.551 \mathrm{~km}^{2}$ has the absolute error, $96.06 \%$ has user's accuracy, 93.18\% has producer's accuracy, 96.43\% has overall accuracy, and 0.8906 is kappa coefficients as shown in Table 6. Though, the index methods, including MNDWI, NDWI, and NDVI provided good accuracies as compared with NDMI method. Instead of all indexed methods, MNDWI provides better results than other methods (NDWI, NDVI, and NDMI) for detecting and extracting surface water body in the Reservoir. Here, the Reservoir provides a lot of benefits for agricultural (food crops), industrial, domestic purpose, and human existing in its surrounding. Thus, it required correcting measurements to avoid any obstacles in the Reservoir to get its original conditions for restoring the Reservoir.

Table 6. Statistical Parameters of Accuracy Assessment of Changes in Surface Water Body

\begin{tabular}{ccccccc}
\hline Method & $\begin{array}{c}\text { Changed water } \\
\text { body }\left(\mathrm{km}^{2}\right)\end{array}$ & $\begin{array}{c}\text { Absolute } \\
\text { Error }\left(\mathrm{km}^{2}\right)\end{array}$ & $\begin{array}{c}\text { Producer's } \\
\text { accuracy }(\%)\end{array}$ & $\begin{array}{c}\text { User's } \\
\text { accuracy }(\%)\end{array}$ & $\begin{array}{c}\text { Overall } \\
\text { accuracy }(\%)\end{array}$ & $\begin{array}{c}\text { Kappa } \\
\text { coefficient }\end{array}$ \\
\hline Reference & 44.000 & 0.000 & 100 & 100 & 100 & 1 \\
NDVI & 44.045 & 0.045 & 89.57 & 91.50 & 92.86 & 0.8096 \\
NDWI & 42.818 & 1.182 & 92.31 & 88.91 & 94.64 & 0.8100 \\
MNDWI & 42.449 & 1.551 & 93.18 & 96.06 & 96.43 & 0.8906 \\
NDMI & 40.622 & 3.378 & 87.59 & 88.96 & 91.67 & 0.7625 \\
\hline
\end{tabular}

\section{CONCLUSION}

The main aim of this study is to detect the spatiotemporal changes of surface water area in Nagarjuna Sagar Reservoir from the period of 1989 to 2017, by the satellite image interpretation and GIS. Using satellite images to extract information regarding Reservoir water area change is faster and more accurate than other observation methods. Several index methods (NDVI, NDWI, MNDWI, and NDMI) were used for detecting and extracting surface water area. The result shows that decreasing surface water area maximum changes occurred about $44.641 \mathrm{~km}^{2}$ in the period 1989 to 2017 . Especially, from 2007 to 2017 the Reservoir lost its surface water area about $36.016 \mathrm{~km}^{2}$. If such decreasing tendency follows continuously the Reservoir will lose its maximum surface water area in near future. The statistical parameters of the accuracy assessment result show that MNDWI provides better results as compared to other index methods (NDVI, NDWI, and NDMI) so that the MNDWI method has good efficient in detecting and extracting surface water body in Nagarjuna Sagar Reservoir. The future scope of these methods could be useful for detecting and extracting (decreasing or increasing) open water surface area in the world with different band wavelengths and different satellite data.

\section{ACKNOWLEDGEMENTS}

We would like acknowledge to the Centre of Excellence (CoE) for utilization of resources and availability of software tools. The grateful thanks to the USGS portal for downloading Landsat data with a free of cost.

\section{REFERENCES}

[1] S. Kaliraj, et al., "Application of remote sensing in detection of forest cover changes using geo-statistical change detection matrices-A case study of devanampatti reserve forest, tamilnadu, India," Nat. Environ. Polluti. Technol., vol. 11, pp. 261-269, 2012.

[2] V. Markogianni, et al., "Land-use and vegetation change detection in plastira artificial lake catchment (Greece) by using remote-sensing and GIS techniques," Int. J. Remote Sens., vol. 34, pp. 1265-1281, 2013.

[3] M. Volpi, et al., "Flooding extent cartography with Landsat TM imagery and regularized Kernel Fisher's discriminant analysis," Comput. Geosci., vol. 57, pp. 24-31, 2013.

[4] B. Brisco, et al., "Sar polarimetric change detection for flooded vegetation," Int. J. Digit. Earth, vol. 6, pp. 103114, 2013. 
[5] Y. O. Ouma and R. Tateishi, "A water index for rapid mapping of shore-line changes of five East African Rift Valley lakes: an empiricalanalysis using Landsat TM and ETM+ data,” Int. J. Remote Sens, vol. 27, pp. 3153-3181, 2006.

[6] S. Lu, et al., "Water body mapping method with HJ-1A/B satellite imagery," Int. J. Appl. Earth Obs. Geoinf., vol. 13, pp. 428-434, 2011.

[7] P. J. J. Desmet and G. Govers, "A GIS procedure for automatically calculating the USLE LS factor on topographically complex landscape units," J. Soil Water Conserv., vol. 51, pp. 427-433, 1996.

[8] W. Zhou and B. Wu, "Assessment of soil erosion and sediment delivery ratio using remote sensing and GIS: A case study of upstream chaobaihe river catchment, north China," Int. J. Sediment Res., vol. 23, pp. 167-173, 2008.

[9] Z. Du, et al., "Estimating surface water area changes using time-series Landsat data in the qingjiang river basin, China," J. Appl. Remote Sens., vol. 6, 2012.

[10] F. Sun, et al., "Comparison and improvement of methods for identifying waterbodies in remotely sensed imagery," Int. J. Remote Sens., vol. 33, pp. 6854-6875, 2012.

[11] Water Body Extraction from Multi-Source Satellite Images. Available online: $\quad$ http://citeseerx.ist.psu.edu/viewdoc/download?doi=10.1.1.301.8033\&rep=rep1\&type=pdf.

[12] H. Xu, "Modification of normalised difference water index (NDWI) to enhance open water features in remotely sensed imagery," Int. J. Remote Sens., vol. 27, pp. 3025-3033, 2006.

[13] Water Body Extraction And Change Detection Based on Multi-Temporal SAR Images. Available online: http://adsabs.harvard.edu/abs/2009SPIE.7498E..96Z.

[14] H. Zhou, et al., "Landscape and water quality change detection in urban wetland: A post-classification comparison method with IKONOS data," Procedia Environ. Sci., vol. 10, pp. 1726-1731, 2011.

[15] Z. Tang, et al., "Extraction of water body based on Landsat TM5 imagery-A case study in the Yangtze river," $A d v$. Inf. Comm. Technol., vol. 393, pp. 416-420, 2013.

[16] W. Li, et al., "A comparison of land surface water mapping using the normalized difference water index from TM, ETM+ and ALI," Remote Sens., vol. 5, pp. 5530-5549, 2013.

[17] S. K. McFeeters, "Using the normalized difference water index (NDWI) within a geographic information system to detect swimming pools for mosquito abatement: a practical approach," Remote Sens., vol. 5, pp. 3544-3561, 2013.

[18] J. W. Rouse, et al., "Monitoring Vegetation Systems in the Great Plains with ERTS (Earth Resources Technology Satellite)," Proceedings of Third Earth Resources Technology Satellite Symposium, Greenbelt, ON, Canada, vol. SP-351, pp. 309-317, 1973.

[19] E. H. Wilson and S. A. Sader, "Detection of forest harvest type using multiple dates of Landsat TM imagery," Remote Sens. Environ., vol. 80, pp. 385-396, 2002.

[20] S. K. McFeeters, "The use of the normalized difference water index (NDWI) in the delineation of open water features,” Int. J. Remote Sens., vol. 17, pp. 1425-1432, 1996. 